\title{
Le Vieil-Évreux - Le Grand Sanctuaire : la basilique
} $\mathrm{n}^{\circ} 17-2381$

Sandrine Bertaudière

\section{(2) OpenEdition}

Édition électronique

URL : http://journals.openedition.org/adlfi/16599

ISSN : 2114-0502

Éditeur

Ministère de la culture

Référence électronique

Sandrine Bertaudière, "Le Vieil-Évreux - Le Grand Sanctuaire : la basilique », ADLFI. Archéologie de la France - Informations [En ligne], Haute-Normandie, mis en ligne le 18 février 2016, consulté le 01 mai 2019. URL : http://journals.openedition.org/adlfi/16599

Ce document a été généré automatiquement le 1 mai 2019.

(c) Ministère de la Culture et de la Communication, CNRS 


\section{Le Vieil-Évreux - Le Grand Sanctuaire : la basilique}

$n^{\circ} 17-2381$

\section{Sandrine Bertaudière}

Lien Atlas (MCC) :

http://atlas.patrimoines.culture.fr/atlas/trunk/index.php?

ap_theme=DOM_2.01.02\&ap_bbox=1.177;48.985;1.250;49.017

1 La dernière année de la fouille triennale 2011-2013 a porté à la fois sur la phase la plus ancienne (période augustéenne), la cour méridionale du monument claudio-antonin, l'occupation pendant l'Antiquité tardive (comblement du puits, et niveaux observés en coupe) et la démolition finale de l'édifice sévérien.

2 La première occupation attestée sur ce site est datée de l'époque augustéenne, vers 10 av. J.-C. Quelques fosses ont été creusées directement dans le terrain naturel. Un sol en silex scelle ensuite ces niveaux et de nouvelles fosses, difficilement interprétables, sont creusées. Elles sont peut-être à dater des années 1-10 apr.J.-C. Aucun élément ne permet de connaître le contexte de ces structures.

3 En ce qui concerne les premiers temples en pierre (vers 50-180 apr. J.-C.), de nouvelles informations ont été apportées sur l'allée installée dans la cour méridionale. Dès sa création à l'époque flavienne, elle est bordée par plusieurs aménagements, dont un pourrait être paysager. Sous l'allée, un système d'adduction et d'évacuation a été mis au jour et a pu permettre d'alimenter en eau un bassin, une fontaine ou une vasque dont il ne reste que les fondations, partiellement dégagées.

Une fois les premiers temples en pierre détruits, les terrassements pour la construction du monument sévérien ont été entrepris. De nouvelles informations ont été apportées sur cette phase, nous renseignant ainsi sur l'organisation de ce chantier gigantesque.

La fouille à l'avant de l'édifice et notamment à l'emplacement du mur de soutènement de la terrasse de la galerie de liaison sud a permis de conforter l'hypothèse selon laquelle le projet initial de la construction de l'édifice avait été revu au cours de la réalisation. Les 
vestiges d'une nouvelle porte ont effectivement été identifiés dans l'angle nord de la terrasse. Cette ouverture n'a été utilisée qu'au moment de la phase de travaux car les soubassements de la terrasse ont ensuite été remblayés pour asseoir le sol de cette dernière. La seconde porte, encore en élévation et de très belle facture, a elle aussi été condamnée.

6 À l'extérieur de l'édifice, le sol avant est réalisé avec les déchets calcaires issus de la construction. Contre le mur de soutènement de la terrasse, une niche, un autel ou un autre aménagement était installé dans l'axe de la terrasse.

7 L'ensemble est ensuite scellé par d'épais remblais d'argile liés à la construction d'un castellum. Les trois temples sévériens sont ceinturés par un large talus d'au moins $14 \mathrm{~m}$ et d'un fossé d'au moins $10 \mathrm{~m}$ de large délimitant le castellum. Dans l'angle sud du temple et de la terrasse de la galerie de liaison sud, d'épais remblais sombres suggèrent que des activités liées au feu étaient très présentes dans cet espace.

Il semble, au vu de la datation de la dernière occupation, que le castellum soit toujours en activité pendant la démolition de l'édifice. En effet, les premiers remblais de démolition fouillés en son intérieur (dans le sous-sol de la cella, et à l'arrière de la galerie de liaison) sont datés par la céramique et les monnaies de la fin du $\mathrm{III}^{\mathrm{e}} \mathrm{s}$. À l'avant de l'édifice, les remblais sont quant à eux datés du milieu $d u \mathrm{IV}^{\mathrm{e}} \mathrm{s}$. Ces différentes datations tendent à montrer que la démolition s'est étalée dans le temps et indiquent vraisemblablement le sens de remblaiement après récupération des matériaux. L'intérieur de l'édifice (en rezde-jardin), semble donc rapidement enseveli par des amoncellements de gravats dont il ne nous restait que les premiers mètres. Les tranchées de récupération, à l'avant de l'édifice, sont ensuite comblées. Ce remblaiement est daté du milieu de $\mathrm{IV}^{\mathrm{e}} \mathrm{s}$. L'avant de la galerie de liaison nord semble avoir été rebouché un peu plus tard, c'est-à-dire vers la fin du IV $v^{\mathrm{e}}$.

La fouille du puits et les différentes études permettent de confirmer l'existence d'un rythme particulier en lien avec la démolition de l'édifice. Quatre séquences ont ainsi été observées (cf. fig.) :

- durant la séquence $\mathrm{D}$, les artéfacts sont associés à la réoccupation du site et semblent témoigner de plusieurs activités de production dans le castellum. Les quelques éléments liés à la démolition semblent plutôt correspondre au nettoyage ponctuel de certaines zones dans le monument. Des éléments en lien avec la première démolition devaient encore joncher le sol et ont pour certains été jetés dans le puits. Les artéfacts mis au jour correspondent effectivement aux éléments récupérés lors de cette première démolition (dallage et placage, fragments de marche et éléments de toiture).

- La séquence $C$ pourrait correspondre au début de la démolition finale. Le castellum est toujours occupé et les objets de la vie quotidienne prédominent, mais les éléments liés au démontage de l'édifice apparaissent en nombre dans cette séquence.

- La séquence $B$ indique que le temple central est démantelé: la toiture, le fronton, l'entablement et la colonnade sont démolis.

- La séquence A enfin, évoque plutôt un nettoyage. Toutes sortes de débris sont alors jetés dans le puits.

Ces différents remblais de démolition ont livré un nombre important de blocs qui ont permis de compléter la restitution architecturale de l'édifice, de préciser les dimensions des différents modules et de localiser les lieux d'approvisionnement en matières premières. 


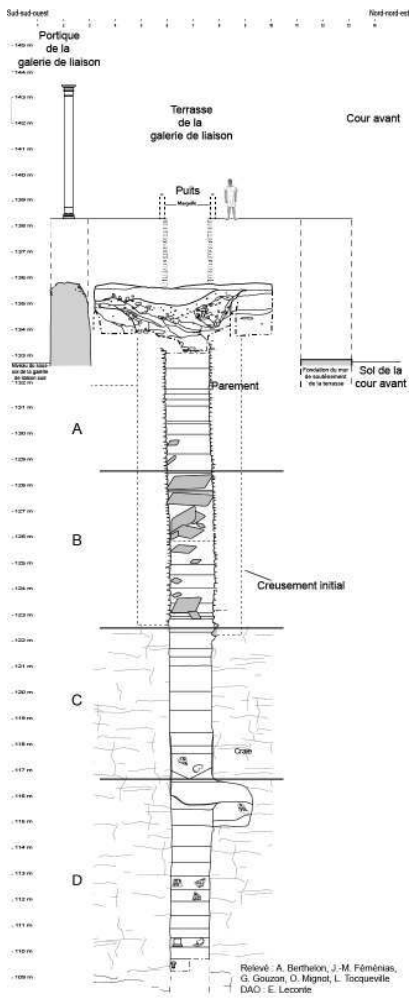

Fig. 01

Coupe du puits

Relevé : A. Berthelon, J.-M. Féménias, G. Gouzon, O. Mignot, L. Tocqueville ; DAO : É. Leconte

INDEX

Index géographique : Normandie, Eure (27), Le Vieil-Évreux

Mots-clés : temple, allée, assainissement, adduction, ville-sanctuaire, terrasse, castellum, démolition, tranchée de récupération, puits operation Fouille programmée (FP)

Index chronologique : Antiquité, Antiquité tardive

\section{AUTEURS}

\section{SANDRINE BERTAUDIÈRE}

Mission Archéologique de l'Eure 